\title{
Self-reported interoceptive awareness in primary care patients with past or current low back pain
}

\author{
This article was published in the following Dove Press journal: \\ Journal of Pain Research \\ 27 May 2013 \\ Number of times this article has been viewed
}

\author{
Wolf E Mehling ${ }^{1,2}$ \\ Jennifer Daubenmier ${ }^{1,3}$ \\ Cynthia J Price ${ }^{5}$ \\ Mike Acree' \\ Elizabeth Bartmess' \\ Anita L Stewart ${ }^{4}$ \\ 'Osher Center for Integrative \\ Medicine, ${ }^{2}$ Department of Family and \\ Community Medicine, ${ }^{3}$ Department of \\ Medicine, ${ }^{4}$ School of Nursing, Institute \\ for Health and Aging, University \\ of California, San Francisco, CA, \\ ${ }^{5}$ School of Nursing, Department of \\ Biobehavioral Nursing and Health \\ Systems, University of Washington, \\ Seattle, WA, USA
}

Background: Mind-body interactions play a major role in the prognosis of chronic pain, and mind-body therapies such as meditation, yoga, Tai Chi, and Feldenkrais presumably provide benefits for pain patients. The Multidimensional Assessment of Interoceptive Awareness (MAIA) scales, designed to measure key aspects of mind-body interaction, were developed and validated with individuals practicing mind-body therapies, but have never been used in pain patients.

Methods: We administered the MAIA to primary care patients with past or current low back pain and explored differences in the performance of the MAIA scales between this and the original validation sample. We compared scale means, exploratory item cluster and confirmatory factor analyses, scale-scale correlations, and internal-consistency reliability between the two samples and explored correlations with validity measures.

Results: Responses were analyzed from 435 patients, of whom $40 \%$ reported current pain. Cross-sectional comparison between the two groups showed marked differences in eight aspects of interoceptive awareness. Factor and cluster analyses generally confirmed the conceptual model with its eight dimensions in a pain population. Correlations with validity measures were in the expected direction. Internal-consistency reliability was good for six of eight MAIA scales. We provided specific suggestions for their further development.

Conclusion: Self-reported aspects of interoceptive awareness differ between primary care patients with past or current low back pain and mind-body trained individuals, suggesting further research is warranted on the question whether mind-body therapies can alter interoceptive attentional styles with pain. The MAIA may be useful in assessing changes in aspects of interoceptive awareness and in exploring the mechanism of action in trials of mind-body interventions in pain patients.

Keywords: interoception, body awareness, low back pain, questionnaire

\section{Background}

Interoception, commonly defined as the sense of the physiologic condition of the body, and interoceptive awareness may play important mediating roles in self-rated health ${ }^{2}$ - particularly in the perception of pain. ${ }^{3,4}$ Pain is intimately entwined with emotions. ${ }^{5,6}$ Craig described the neurological pathways by which pain activates some of the same cortex areas as interoception does. ${ }^{7}$ The close similarities between pain and interoception in their neural connections and activated brain regions led Craig to the notion that pain could be viewed as a "homeostatic emotion." Emotions include a felt, somatosensory aspect that may become conscious in interoceptive awareness. ${ }^{9,10}$ As with emotion regulation, attention regulation is a key element of interoceptive awareness. Given the close relationships between pain, emotion, and interoceptive awareness, further exploration of interoceptive awareness in a clinical pain population is warranted. 
A pain patient can focus attention (eg, on her low back pain), in quite different ways: (1) ignore the pain (endurance) ${ }^{11}$ (2) focus on it with worry and anxiety-driven hypervigilance (fear-avoidance); ${ }^{12}$ or (3) focus on it with mindful attention. ${ }^{13}$ These different styles of attention or distraction, respectively, have been found to have a major impact on the perceived intensity of chronic pain. ${ }^{14-20}$ And psychologists studying the effect of mindfulness on emotions and pain have pointed out that:

$[\ldots]$ one problem in chronic pain is not only the pain itself, but $[\ldots]$ the averting of attention from, the regions that give rise to painful sensations, either through deliberate distraction, or by thinking about the pain (conceptually) rather than experiencing the sensations directly. ${ }^{21}$

Attention Regulation thus appears to be a major element of interoception with potential applications for pain management. A recent study showed that focusing on sensory/discriminative aspects of experimental pain might be a useful pain regulation strategy when severe pain is expected. ${ }^{20}$ The authors suggested that directing attention in specific ways toward sensations of chronic pain may be a promising new way of coping with chronic pain and awaits longitudinal studies in a clinical setting.

Interoceptive awareness has been conceptualized in various ways using different terms (eg, somatic awareness, interoceptive awareness, body awareness [see a detailed discussion in Mehling et al] $]^{22}$ ). In psychology and neuroscience, interoceptive awareness has commonly been defined as the sense of the physiological condition of the body. ${ }^{23}$ In clinical medicine, body awareness has been defined as the ability to recognize subtle body cues. ${ }^{24}$ In this study we are using Cameron's conceptualization of interoception (with or without awareness) as "the afferent information that arises from anywhere and everywhere within the body ... [involving] higher mental processes such as emotions, conscious awareness, and behavior." ${ }^{25}$ This conceptualization broadens the former definition by including higher order psychological processes. In an attempt to integrate the various views from different disciplines, and following suggestions by other authors, ${ }^{26}$ in this study we use the term in the broader conceptualization by Cameron and consider this as interchangeable with earlier definitions of "body awareness." 27

Interoceptive awareness has been examined in its relationship to pain, primarily with objective measures, such as the heartbeat detection task, measuring the interoceptive accuracy of the perception of heartbeat sensations. A major limitation of this objective measure is its inability to detect changes that can be expected from mindfulness and other mind-body trainings. ${ }^{28-30}$ Interoceptive awareness includes changes in interoceptive-awareness qualities beyond accuracy, ${ }^{31}$ thus a self-report measure that taps into the subjectively experienced aspects of interoceptive awareness in mind-body interventions ${ }^{32}$ is needed.

Furthermore, interoceptive awareness has been studied, mostly using pain paradigms of acute experimental pain. Few studies have examined interoceptive awareness and attention regulation with directing attention toward pain sensations in clinical pain patients ${ }^{15}$ (overview in Johnston et $\mathrm{al}^{20}$ and Flor $\left.^{33}\right)$. Clinical trials of mind-body therapies, such as mindfulness meditation, yoga, Tai Chi, and Feldenkrais, for patients with pain, including low back pain, have provided encouraging results for these approaches that claim to improve body awareness as one potential mechanism of action for their purported benefits (Table 1). However, to examine the latter assertion, a measure for body awareness or interoceptive awareness that has been validated with pain patients is needed.

The Multidimensional Assessment of Interoceptive Awareness (MAIA) is a new 32-item multidimensional self-report instrument designed for use in research studies for which there is the need to measure key aspects of mindbody interaction, namely, interoceptive awareness. ${ }^{22}$ The initial development (focus groups and expert panel) and preliminary validation (field-test sample) of the MAIA was done primarily with individuals familiar with the concept of bodily awareness, either as students, patients, or instructors of therapeutic approaches that explicitly aim to enhance bodily awareness, including meditation, ${ }^{34}$ yoga, Tai Chi, and Feldenkrais. ${ }^{32}$ Eight MAIA scales were constructed to measure different modes of attention toward bodily sensations (including pain) with the goal of distinguishing between beneficial and maladaptive interoceptive attention

Table I Mind-body therapies purportedly enhancing body awareness and studied in clinical research that use pain as primary outcome

\begin{tabular}{|c|c|c|}
\hline $\begin{array}{l}\text { Therapeutic } \\
\text { approach }\end{array}$ & Patients with & References \\
\hline$\overline{\text { Yoga }}$ & Low back pain & 58 \\
\hline $\begin{array}{l}\text { Mindfulness/ } \\
\text { meditation }\end{array}$ & Chronic pain; fibromyalgia & $60-63$ \\
\hline $\begin{array}{l}\text { Body awareness } \\
\text { therapy/program }\end{array}$ & $\begin{array}{l}\text { Low back pain, chronic pelvic pain, } \\
\text { fibromyalgia, musculoskeletal pain }\end{array}$ & $64-68$ \\
\hline $\begin{array}{l}\text { Body-oriented } \\
\text { therapy }\end{array}$ & Chronic pain & 69 \\
\hline Alexander method & Low back pain & 70,71 \\
\hline Breath therapy & Low back pain & 72 \\
\hline
\end{tabular}


styles. The initial item pool was based on therapists' and patients' focus groups and expert consensus using an initial operational definition for bodily awareness that was iteratively developed into a conceptual framework reflected in the eight scales. These scales of three to seven items each, were defined as follows:

- Noticing-awareness of uncomfortable, comfortable, and neutral body sensations

- Not Distracting - tendency not to ignore or distract oneself from sensations of pain or discomfort

- Not Worrying - tendency not to worry or feel emotional distress with sensations of pain or discomfort

- Attention Regulation - ability to sustain and control attention to body sensation

- Emotional Awareness - awareness of the connection between body sensations and emotional states

- Self-Regulation - ability to regulate psychological distress by attention to body sensations

- Body Listening - active listening to the body for insight

- Trusting - experiences of one's body as safe and trustworthy.

The prefix "not" for the labels "Not Distracting" and "Not Worrying" is owed to our intention that, for every scale, higher scores mean higher levels of awareness. For further details, we refer readers to the original publication. ${ }^{22}$ Because several MAIA scales may contribute to the assessment of patients with pain and their pain-related emotions, coping styles, and interoceptive attention styles, and because the conceptual framework and specific items were designed to reflect awareness of pain, we decided to apply the MAIA scales and explore their performance among primary care patients who had experienced low back pain (LBP).

Measuring key aspects of interoceptive Attention Regulation may be essential to move forward research on therapies for chronic pain patients. The purpose of this study is twofold: (1) describe results of a confirmatory factor analysis of the scale structure and the psychometric characteristics of the MAIA in primary care patients with past or current LBP, including internal-consistency reliability, item-scale correlations, variability, and scale-scale correlations; and (2) explore the construct validity of the MAIA scales by comparing levels of self-reported interoceptive awareness between the mind-body therapy-naïve primary care patients with past or current LBP and mind-body therapy-experienced individuals from the original validation study $^{22}$ and by examining correlations of the MAIA scales with several validity variables.

\section{Methods Setting and population}

The study took advantage of an ongoing prospective cohort study conducted by the first author and used the follow-up assessment of patients who had presented with narrowly defined acute LBP with or without sciatica in primary care clinics 2 years earlier, the Prognosis of Pain (POP) study. ${ }^{35}$ Briefly, the population originally surveyed was a sample of patients seen in primary care clinics of a large health maintenance organization (Kaiser Permanente Northern California, CA, USA), which represented the socioeconomic and ethnic diversity of the San Francisco Bay area. Using electronic medical records, patients seen for LBP in a primary care clinic around the area were sent a written invitation to join the study, by mail the next day. Respondents were interviewed over the phone at baseline $(\mathrm{N}=605)$ and 6 months $(\mathrm{N}=521)$. For the 2-year follow-up, POP study participants had agreed to be contacted again and, when reached $(\mathrm{N}=443)$, were given a choice between a phone interview and an Internet-based survey using Health Insurance Portability and Accountability Act-compliant SurveyGizmo ${ }^{36}$ Approved by the Institutional Review Board of the University of California, San Francisco, the survey was conducted between July 2010 and November 2010 .

Because one aim is to compare results to the sample on which the MAIA was developed, we briefly describe that sample here, although details on that sample are published elsewhere. ${ }^{22}$ Using international listservs from leading mind-body therapy teaching institutions, invitations were sent by email to participate in a Web-based survey using SurveyGizmo between November 2010 and December 2010. The recruitment was organized in a way that we obtained two subgroups: About one-half of the surveyed individuals had at least 20 hours of teaching in meditation, yoga, Tai Chi, Feldenkrais, or other mind-body approaches; the other half had been teaching one of these methods for at least 5 years and was highly experienced in one of these methods.

\section{Measures}

\section{Pain-related measures}

We first ascertained the pain status of the participants using several pain-related self-report measures: General perceived recovery, with six answering options - fully recovered, much improved, slightly improved, same, slightly worse, and much worse $;{ }^{37}$ average LBP in the past week by an 11-point numeric rating scale, and identified three subgroups of respondents: (1) Recovered; patients who are fully recovered by self-report 
after an episode of acute LBP (answered "fully recovered" on the general perceived recovery); (2) Not recovered without pain; patients who are not recovered by self-report but are without LBP in the past week (all other answers on general perceived recovery [GPR] and 0 on the numeric rating scale); and (3) Current pain; patients who report current pain (all other answers on GPR and $>0$ on the numeric rating scale), having either recurrent or persistent pain after an episode of acute LBP 2 years earlier.

Prespecified pain-related and psychological questions were skipped if participants self-rated as fully recovered. Participants were asked whether they had practiced a mind-body therapy, such as yoga or meditation, during the follow-up period to be able to separate these individuals from mind-body therapy-naïve participants in the analyses.

\section{MAIA}

For further details about the systematic development of this measure we refer readers to the original publication. ${ }^{22}$ In the original mind-body-experienced sample, the MAIA showed acceptable psychometric properties of internal consistency reliability (alphas for the eight scales: $0.69 ; 0.66$; $0.67 ; 0.87 ; 0.82 ; 0.83 ; 0.82 ; 0.79)$ and relatively low scalescale correlations indicating independence (0.16 to 0.60$){ }^{22}$ Confirmatory factor analysis showed a good model fit, and evidence of construct validity was obtained by confirmation of hypotheses regarding comparisons between known groups (less versus highly experienced in mind-body therapies), correlations with validity scales of related constructs, such as mindfulness, anxiety sensitivity, catastrophizing, body responsiveness, body connection, and emotion regulation, and associations with a clinical outcome, trait anxiety.

Psychological measures (Table S1) were originally chosen at inception two years earlier to assess score changes in items included to measure changes in predictors of chronic pain. However, several measures provided an opportunity to explore the construct validity of the MAIA scales. These included: (1) the four-item Perceived Stress Scale (PSS) ${ }^{38}$ (2) depression by a single item from the Örebro Musculoskeletal Pain Screening Questionnaire (ÖMPSQ) ${ }^{39} /$ Heidelberger Kurz-Fragebogen (HKF); ${ }^{40}$ (3) fear-avoidance beliefs by one item from Fear-Avoidance Beliefs Questionnaire (FABQ); ${ }^{41}$ (4) catastrophizing by a single item from the Coping Strategies Questionnaire (CSQ) ${ }^{42}$ asked of all participants; (5) catastrophizing by a five-item composite measure we created, including the single item as well as four items asked only in the Current Pain subgroup, two from the Pain Catastrophizing Scale (PCS) ${ }^{43}$ and two from HKF; (6) ignoring coping style and positive distracting coping style by single items from the CSQ; and (7) recovery expectancy by a single item from the ÖMPSQ. Patients who were fully recovered were asked these questions using past tense (eg, "when you had pain").

\section{Analyses}

Confirmatory factor analysis (CFA) on the MAIA scales was done by Mplus Version 5.21 (Muthén and Muthén, Los Angeles, CA, USA). ${ }^{44}$ All other statistical analyses were conducted using SAS (SAS Institute Inc, Cary, NC, USA). To understand the CFA results better, we also conducted exploratory item cluster analyses using SAS PROC VARCLUS, a method of principal components analysis with quartimax rotation for splitting of the item pool into clusters. For a more detailed description, see Mehling et al. ${ }^{22}$

Internal consistency reliability of the MAIA was assessed with Cronbach's alphas. Scale-scale correlations were assessed by Pearson's coefficients.

Construct validity was explored by examining correlations between the MAIA scales and measures of the LBP-related clinical and psychological parameters described above. We expected several correlations: the Not Worrying scale to be negatively correlated with catastrophizing, perceived stress, depression, and fear-avoidance; the Not Distracting scale to be negatively correlated with ignoring coping style; the Self-Regulation and Trusting scales to be correlated negatively with perceived stress. We assessed correlations in the total sample as well as for the three pain-related subgroups to explore whether current pain patients differ from past pain patients in this primary care population.

In addition, we compared MAIA scale means between the POP sample of primary care patients ${ }^{35}$ and the original validation sample of experienced mind-body trainees ${ }^{22}$ by $t$ tests and analysis of covariance to account for differences in sample characteristics. All MAIA scales are scored such that higher scores indicate higher degrees of awareness. Thus, for the two negatively labeled scales (Not Distracting; Not Worrying), higher scores mean more awareness, eg, less distracting. We expected that mind-body experienced subjects would score higher on all MAIA scales, with larger differences for Not Distracting, Emotional Awareness, Attention Regulation, and Self-Regulation. Improvements in these dimensions had been suggested by instructors for mind-body approaches and their patients. . $2,32,34^{2}$ We also compared MAIA scale means between the three subgroups - Recovered; Not recovered but without pain; Current pain - by $t$ tests and analysis of covariance. 
Here, we had no clear hypotheses and wanted to explore whether these pain-related subgroups differed on MAIA scale scores. We were particularly interested to learn more about the subgroup of patients who, despite not having any current pain, declared that they had not completely recovered. Lastly, we did sensitivity analyses to see whether the primary care patients, who had practiced yoga, were confounding these analyses.

\section{Results}

Demographics and clinical parameters of the sample of 443 primary care patients (POP Study) and the 318 students and teachers of mind-body therapies (original study) are summarized in Table 2 and published in more detail elsewhere. ${ }^{22,35}$ The primary care sample was slightly older, less female, more ethnically diverse, and less educated than the original validation sample.

Table 2 Subject characteristics in two samples

\begin{tabular}{|c|c|c|}
\hline Characteristic & $\begin{array}{l}\text { POP total sample } \\
\text { (“Pain") } \\
\mathbf{N}=435\end{array}$ & $\begin{array}{l}\text { "Mind-body" } \\
\text { sample } \\
\mathbf{N}=325\end{array}$ \\
\hline Sex (\% female) & 53 & 79 \\
\hline Average age, mean $\pm S D$ & $54 \pm 12$ & $48 \pm 12$ \\
\hline \multicolumn{3}{|l|}{ Race/ethnicity (\%) } \\
\hline Asian American & 11 & 5 \\
\hline African American & 8 & 2 \\
\hline Latino & 6 & 4 \\
\hline White & 68 & 88 \\
\hline Other & 7 & $<1$ \\
\hline \multicolumn{3}{|l|}{ Education (\%) } \\
\hline High school & 10 & $<1$ \\
\hline Some college & 26 & $<1$ \\
\hline College degree & 36 & 37 \\
\hline Graduate school & 28 & 52 \\
\hline \multicolumn{3}{|c|}{ Disability due to back pain, mean $\pm \mathbf{S D}^{\mathbf{a}}$} \\
\hline Total sample ${ }^{c}$ & $4.4 \pm 5.3$ & \\
\hline Recovered $^{d}$ & $1.1 \pm 2.4$ & - \\
\hline $\begin{array}{l}\text { Not recovered } \\
\text { without pain }\end{array}$ & $3.0 \pm 3.9$ & - \\
\hline Current pain ${ }^{f}$ & $8.3 \pm 5.6$ & - \\
\hline \multicolumn{3}{|c|}{ Pain level at time of survey, mean $\pm \mathbf{S D}^{\mathrm{b}}$} \\
\hline Total sample ${ }^{c}$ & I.5 (2.3) & - \\
\hline Fully recovered ${ }^{d}$ & $0 \mathrm{~g}$ & - \\
\hline $\begin{array}{l}\text { Not fully recovered, } \\
\text { no current pain }\end{array}$ & $0^{\mathrm{g}}$ & - \\
\hline Current pain ${ }^{f}$ & $3.7(2.2)$ & - \\
\hline
\end{tabular}

Notes: Subject characteristics in POP total sample and in original measurement development sample ("mind-body" sample). Pain measures not applicable to mindbody sample. a Roland-Morris Disability Scale, range 0-24, higher is more disability; baverage pain in past week by numeric rating scale 0-10; 'total sample $(N=435)$; ${ }^{d}$ recovered ( $\left.N=166 ; 38 \%\right)$; ${ }^{e}$ not recovered without pain ( $\left.N=97 ; 22 \%\right)$; ${ }^{\text {c}}$ current pain $(\mathrm{N}=172 ; 39 \%)$; ${ }^{\mathrm{a}} \mathrm{z}$ zero was inferred for fully recovered and no current pain subsamples.

Abbreviations: SD, standard deviation; POP, Prognosis of Pain study.
The 443 participants in the POP follow-up sample were patients who had suffered an episode of acute LBP and had sought medical advice for LBP 2 years prior. The final sample, those who responded to at least half of all MAIA items, was reduced to 435. Of these, 166 Recovered; 97, Not recovered but were without pain; and 172, Current pain. One hundred sixty-five participants provided answers in phone interviews and 270 via a parallel online survey.

\section{Confirmatory factor and exploratory cluster analyses}

Different from the original validation sample, the CFA did not converge for the entire POP sample or for any of the recoveryrelated subgroups. However, CFAs did converge when we separately assessed participants responding to the survey by Internet or those responding by phone interviews. To further clarify the reason for nonconvergence of the CFA in the total sample, we applied the oblique exploratory item cluster analysis (EICA) method of splitting the item pool into clusters that are comparable to exploratory factors and found that the scale of Not Distracting as a whole, and within that scale primarily Item 5, was causing the convergence problem for the CFA. This item loaded negatively on its factor in the phone sample $(-0.10)$ and positively in the Internet sample (0.32).

Phone interviewers had reported that participants had difficulty with the language of Item 5 ("I do not notice physical tension or discomfort until they become more severe"). In the covariance matrix for the latent variables, the Not Distracting scale was independent of all other MAIA scales. Excluding this scale (Item 5-Item 7), a CFA conducted in the total sample on items from the seven remaining scales converged and is shown in Table 5, with comparative fit index (CFI) of 0.88 and root mean square error of approximation (RMSEA) of 0.07 . When we compared the EICAs between our samples, we found that items related to ignoring pain or discomfort (Not Distracting) clustered with items related to worry (Not Worrying) in mind--body trained individuals but clustered separately in pain patients.

Allowing items to split into clusters with an eigenvalue of at least 1.0, the EICA delivered a seven-factor model, generally consistent with the original scales but without the separate Body Listening scale, of which one item drifted toward the Emotional Awareness and two to the Self-Regulation scale. All other scales were confirmed in their integrity with exception of the single "homeless" Item 5, attaching itself to Noticing but essentially without real contribution to this cluster $\left(R^{2}=0.16\right)$. The entire EICA cluster model explained 0.61 of the total variance. Conducting the cluster analysis 
separately on the three recovery-related subsamples provided identical results, with the exception of Item 5 moving between various clusters (results not shown).

\section{Means and internal consistency}

MAIA scale means with standard deviations, range of observed values, and Cronbach's alphas are presented in Table 3. Values are presented for the entire sample as well as for the three subgroups, according to recovery and pain. In the total sample, Cronbach's alphas for six of the eight MAIA scales ranged from 0.74 to 0.90 , however, alphas were low for Not Worrying (0.58), and Not Distracting scale (0.48). For each scale, alphas were generally similar in the subgroups to the total sample. Phone survey interviewers had noted that some participants had difficulties with responding to negatively worded items of the Not Distracting and Not Worrying scales. In contrast, Internet survey participants saw the item response scales for each item with numeric ratings and labeled endpoints, reducing potential confusion in responding to negatively worded items. Therefore, we calculated separate alphas by administration method: For the least-reliable Not Distracting scale, alphas were 0.24 in the phone and 0.59 in the Internet samples.

\section{Scale-scale correlations}

The MAIA scale-scale correlations are presented in Table 4. The highest correlations were between Self-Regulation and Body Listening (0.72) and between Emotional Awareness and Body Listening (0.66). Not Distracting and Not Worrying scales did not correlate with each other $(r=-0.10)$ or with any other MAIA scale $(r \mathrm{~s} \leq 0.16)$. Compared with the original validation sample, correlations were similar. One difference between the samples involved the Not Distracting and Not Worrying scales, which in mind-body trained individuals ${ }^{22}$ had correlated positively with each other $(r=0.33)$ and three other MAIA scales, Attention Regulation, Self-Regulation, and Trusting ( $r-0.19$ to $-0.35 ; P<0.001)$.

For the Not Distracting scale, item-scale correlations were between 0.31 and 0.52 in the Internet sample and between 0.01 and 0.22 in the phone sample. Similarly, the scale's item-item correlations were between 0.19 and 0.44 in the Internet sample and between 0.02 and 0.32 in the phone sample.

\section{Correlations with psychological and pain-related variables}

Table 6 shows the correlations between the MAIA scales and psychological and pain-related variables (with expected correlations shaded in gray). Results are shown for the entire sample and for the three subgroups. As expected,
Not Worrying was moderately negatively correlated with catastrophizing (single item as well as five-item composite), perceived stress (PSS), and depression (ÖMPSQ/HKF). Also as expected, the Not Distracting scale strongly negatively correlated with ignoring coping style (CSQ). The highest magnitude of correlations of Not Distracting and Not Worrying with these quasi-validity measures was in the current pain subsample. Not Worrying also showed a moderate negative correlation with fear-avoidance, but only in the nonrecovered without pain subgroup.

The Trusting scale was significantly negatively correlated with perceived stress (PSS) and depression. Self-Regulation correlated significantly negatively with perceived stress and positively with the positive distracting style of coping. MAIA scales' correlations with recovery expectations were very small (all $<0.20$ ). Body Listening, Emotional Awareness, Attention Regulation, and Noticing MAIA scales were not related to any of the psychological or pain-related measures.

For the correlations between MAIA scales and the above described validation measures, the subgroup of patients, who described themselves as not recovered, despite not having any current pain, stood out in several ways: Across the three pain- and recovery-related subgroups, this not recovered group scored lowest on Not Worrying (highest in worrying) and had the strongest negative correlations across groups for Not Worrying with catastrophizing and fear-avoidance, and for Self-Regulation with perceived stress and depression. This group had the lowest negative correlations between Not Worrying and depression as well as for Ignoring and Not Distracting.

\section{Differences between known groups}

Comparing the primary care POP study sample with the mind-body experienced sample, scores in the latter sample were significantly higher on all eight scales (Table 7 , unadjusted means). Adjusting for demographic differences in age, sex, ethnicity, and education provided similar means and $P$-values (data not shown).

Seventy-one POP study participants reported having an ongoing mind-body practice, such as yoga. The differences with the original mind-body sample were generally more pronounced when we excluded those with an ongoing mindbody practice from the primary care POP study sample. Primary care POP study patients who reported a regular practice of a mind-body technique showed overall MAIA scores either similar to the original mind-body experienced sample or somewhere between the original mind-body experienced sample and the nonpracticing participants of the POP 
Table 3 Reliability, item-scale correlations, and descriptive statistics for MAIA scales in total sample and three pain group subsamples

\begin{tabular}{|c|c|c|c|c|c|c|}
\hline Scale & \# of items & Alpha & $\begin{array}{l}\text { Range of item-scale } \\
\text { correlations }\end{array}$ & Mean (SD) & Observed range $^{a}$ & $\mathbf{N}$ \\
\hline Noticing & 4 & & & & & \\
\hline Total sample & & 0.74 & $0.48-0.60$ & $3.58(1.16)$ & $0-5$ & $30 I^{\mathrm{b}}$ \\
\hline Recovered & & 0.74 & $0.51-0.62$ & $3.60(1.17)$ & $0-5$ & 122 \\
\hline Not recovered & & 0.73 & $0.42-0.65$ & $3.68(1.10)$ & $0.8-5$ & 66 \\
\hline \multicolumn{7}{|l|}{ without pain } \\
\hline Current pain & & 0.75 & $0.47-0.6 \mathrm{I}$ & 3.49 (1.19) & $0-5$ & 113 \\
\hline Not Distracting & 3 & & & & & \\
\hline Total sample & & 0.48 & $0.18-0.40$ & $1.91(1.00)$ & $0-5$ & 434 \\
\hline Recovered & & 0.38 & $0.10-0.30$ & $2.03(1.00)$ & $0-5$ & 166 \\
\hline Not recovered & & 0.62 & $0.36-0.48$ & $1.88(1.07)$ & $0-5$ & 96 \\
\hline \multicolumn{7}{|l|}{ without pain } \\
\hline Current pain & & 0.46 & $0.16-0.46$ & $1.82(0.96)$ & $0-4.7$ & 172 \\
\hline Not Worrying & 3 & & & & & \\
\hline Total sample & & 0.58 & $0.32-0.5 \mathrm{I}$ & $2.91(1.08)$ & $0-5$ & 434 \\
\hline Recovered & & 0.52 & $0.27-0.43$ & $2.80(1.01)$ & $0-5$ & 166 \\
\hline Not recovered & & 0.55 & $0.28-0.55$ & $2.69(1.09)$ & $0-5$ & 96 \\
\hline \multicolumn{7}{|l|}{ without pain } \\
\hline Current pain & & 0.63 & $0.37-0.55$ & $3.16(1.10)^{*}$ & $0-5$ & 172 \\
\hline Attention Regulation & 7 & & & & & \\
\hline Total sample & & 0.88 & $0.60-0.73$ & $3.04(1.05)$ & $0-5$ & 433 \\
\hline Recovered & & 0.87 & $0.60-0.76$ & $3.11(1.04)$ & $0-5$ & 165 \\
\hline Not recovered & & 0.87 & $0.55-0.76$ & $2.93(1.05)$ & $0-5$ & 97 \\
\hline \multicolumn{7}{|l|}{ without pain } \\
\hline Current pain & & 0.89 & $0.59-0.78$ & $3.03(1.07)$ & $0-5$ & 171 \\
\hline Emotional Awareness & 5 & & & & & \\
\hline Total sample & & 0.90 & $0.63-0.84$ & $3.42(1.20)$ & $0-5$ & 434 \\
\hline Recovered & & 0.92 & $0.76-0.89$ & $3.36(1.27)$ & $0-5$ & 165 \\
\hline Not recovered & & 0.87 & $0.45-0.84$ & $3.49(1.17)$ & $0-5$ & 97 \\
\hline \multicolumn{7}{|l|}{ without pain } \\
\hline Current pain & & 0.87 & $0.59-0.81$ & $3.45(1.15)$ & $0-5$ & 172 \\
\hline Self-Regulation & 4 & & & & & \\
\hline Total sample & & 0.86 & $0.64-0.76$ & $2.93(1.19)$ & $0-5$ & 432 \\
\hline Recovered & & 0.87 & $0.67-0.78$ & $2.96(1.22)$ & $0-5$ & 165 \\
\hline Not recovered & & 0.80 & $0.58-0.66$ & $3.07(1.04)$ & $0.3-5$ & 96 \\
\hline \multicolumn{7}{|l|}{ without pain } \\
\hline Current pain & & 0.86 & $0.64-0.79$ & $2.82(1.22)$ & $0-5$ & 171 \\
\hline Body Listening & 3 & & & & & \\
\hline Total sample & & 0.83 & $0.65-0.74$ & $2.5 \mathrm{I}(1.28)$ & $0-5$ & 433 \\
\hline Recovered & & 0.84 & $0.64-0.76$ & $2.52(1.29)$ & $0-5$ & 164 \\
\hline Not recovered & & 0.84 & $0.70-0.73$ & $2.66(1.26)$ & $0-5$ & 97 \\
\hline \multicolumn{7}{|l|}{ without pain } \\
\hline Current pain & & 0.81 & $0.56-0.73$ & $2.43(1.30)$ & $0-5$ & 172 \\
\hline Trusting & 3 & & & & & \\
\hline Total sample & & 0.78 & $0.56-0.65$ & $3.91(0.97)$ & $0-5$ & 432 \\
\hline Recovered & & 0.82 & $0.56-0.76$ & $3.99(1.02)$ & $0-5$ & 163 \\
\hline Not recovered & & 0.72 & $0.48-0.64$ & $4.00(0.83)$ & I.3-5 & 97 \\
\hline \multicolumn{7}{|l|}{ without pain } \\
\hline Current pain & & 0.77 & $0.58-0.65$ & $3.78(0.97)$ & $0.3-5$ & 172 \\
\hline
\end{tabular}

Notes: aPossible range $0-5$; bdue to administrative error, 135 participants were not asked the 4 items of the Noticing scale, resulting in a lower $\mathrm{N}$ for this scale. $*$ Significant subgroup differences (analysis of variance: $P<0.001$ ).

Abbreviations: SD, standard deviation; MAIA, Multidimensional Assessment of Interoceptive Awareness.

sample. The exception was scores for the Not Distracting scale, for which there was no difference between practicing and nonpracticing POP study primary care patients.

When we compared the three subgroups of Recovered, Not recovered without pain, and Current pain, differences were insignificant for seven of eight scales. On the Not Worrying scale patients, who reported not being fully recovered, despite having no current pain, scored lower than patients with recurrent or persistent chronic pain since 2 years ( $P=0.0005)$, indicating a higher tendency to worry about 
Table 4 Pearson product moment correlations among MAIA scales in total sample $(\mathrm{N}=30 \mathrm{I}-434)$

\begin{tabular}{|c|c|c|c|c|c|c|c|c|}
\hline Scale & Noticing* & $\begin{array}{l}\text { Not } \\
\text { Distracting }\end{array}$ & $\begin{array}{l}\text { Not } \\
\text { Worrying }\end{array}$ & $\begin{array}{l}\text { Attention } \\
\text { Regulation }\end{array}$ & $\begin{array}{l}\text { Emotional } \\
\text { Awareness }\end{array}$ & Self-Regulation & $\begin{array}{l}\text { Body } \\
\text { Listening }\end{array}$ & Trusting \\
\hline Noticing & - & & & & & & & \\
\hline Not Distracting & 0.05 & - & & & & & & \\
\hline Not Worrying & -0.03 & -0.10 & - & & & & & \\
\hline Attention & 0.36 & -0.01 & 0.06 & - & & & & \\
\hline \multicolumn{9}{|l|}{ Regulation } \\
\hline Emotional & 0.45 & 0.03 & -0.13 & 0.44 & - & & & \\
\hline \multicolumn{9}{|l|}{ Awareness } \\
\hline Self-Regulation & 0.42 & -0.02 & 0.13 & 0.57 & 0.60 & - & & \\
\hline Body Listening & 0.44 & 0.06 & -0.07 & 0.56 & 0.66 & 0.72 & - & \\
\hline Trusting & 0.26 & -0.07 & 0.16 & 0.41 & 0.29 & 0.50 & 0.44 & - \\
\hline
\end{tabular}

Notes: *Due to administrative error, 135 participants were not asked the four items of the Noticing scale, resulting in a lower $\mathrm{N}$ for correlations with this scale. Correlations are significant if $>0.22$ at $P<0.000$ I; $>0.19$ at $P<0.00$ I; $>0.16$ at $P<0.005$.

Abbreviation: MAIA, Multidimensional Assessment of Interoceptive Awareness.

sensations of pain and discomfort. This subgroup showed only a mildly elevated disability score (3.0 \pm 3.9$)$, higher than the one in the fully recovered group $(1.1 \pm 2.4)$, but clearly below the current pain group $(8.3 \pm 5.6)$.

\section{Discussion}

This is the first assessment of self-reported interoceptive awareness in a clinical sample of patients with past or current LBP by application of the MAIA scales. We tested the performance of the MAIA scales in a population of primary care patients who had experienced a new episode of acute LBP 2 years earlier. Of these, 38\% were fully recovered at the time of the survey, whereas $22 \%$ reportedly had not fully recovered but were without current pain, and $40 \%$ were still suffering chronic or recurrent pain.

\section{Construct validity}

The Not Distracting scale includes an item (Item 5) that in exploratory cluster analysis did not group with any of the scales. For the CFA, in which items are forced into a scale, the Not Distracting scale prevented the convergence of the eight-factor model. After excluding the Not Distracting scale, the CFA converged with acceptable factor loadings and model fit. As mentioned above, our interviewers noted that some participants had difficulties answering the negatively worded items over the phone and speculated that it was easier for participants taking the survey online. Online, it was easier simply to reread the question and have a visual for all answering options. We therefore conducted CFAs separately for the phone interview and Internet subsamples: Once separated, both subsample CFAs converged, even with the Not Distracting scale included. Exploratory cluster analysis, in which items are free to cluster with each other across scales, confirmed the MAIA scales for this population, again with the exception of Item 5, suggesting this item may have to be dropped or reworded in any future studies.

The two scales of Not Distracting and Not Worrying are the only scales with negatively worded and reverse scored items (all three Not Distracting items; two of three Not Worrying items). Consistent with the observation of phone interviewers regarding the difficulties in answering Item 5, the EICA showed a strong modification index (0.23) for Item 5 only in the phone sample.

\section{Means and internal consistency}

Scale means and observed ranges indicated fairly good variability in the entire sample and the three pain and recovery-related subgroups. Cronbach's alphas were acceptable for six of the eight scales. For the three-item scales with low alphas - Not Distracting and Not Worrying - lower alphas for phone participants compared to the Internet participants were consistent with what interviewers had suspected; namely, that questions presented over the phone with difficult or negative wording (eg, Item 5, discussion follows), and without visual cues for answering options, may have been more difficult to answer. We note, however, that despite low internal consistency, there were numerous substantial correlations between these two scales and several validity measures (Table 6), and the two scales discriminated between some of our known groups (Table 7). Thus, the low reliability did not, in fact, limit the magnitude of their associations with other measures. Nonetheless, as in our earlier study, these two scales warrant further attention to improve their reliabilities. ${ }^{22}$

\section{Convergent validity}

Scale-scale correlations were in the desired range except that the Not Distracting and the Not Worrying scales had the lowest correlations with each other and all other MAIA 
Table 5 Items and standardized CFA loadings for MAIA scales in total sample

\begin{tabular}{|c|c|c|}
\hline & $\begin{array}{l}\text { Standardized } \\
\text { loading }\end{array}$ & SE \\
\hline \multicolumn{3}{|l|}{ Noticing } \\
\hline I. When I am tense, I notice where the tension is located in my body. & 0.69 & 0.04 \\
\hline 2. I notice when I am uncomfortable in my body. & 0.62 & 0.04 \\
\hline 3. I notice where in my body I am comfortable. & 0.66 & 0.04 \\
\hline 4. I notice changes in my breathing, such as whether it slows down or speeds up. & 0.58 & 0.04 \\
\hline \multicolumn{3}{|l|}{ Not Distracting } \\
\hline 5. I do not notice (I ignore) physical tension or discomfort until they become more severe. & Dimension not included & \\
\hline \multicolumn{3}{|l|}{ 6. I distract myself from sensations of discomfort. } \\
\hline \multicolumn{3}{|l|}{ 7. When I feel pain or discomfort, I try to power through it. } \\
\hline \multicolumn{3}{|l|}{ Not Worrying } \\
\hline 8. When I feel physical pain, I become upset. & 0.49 & 0.05 \\
\hline 9. I start to worry that something is wrong if I feel any discomfort. & 0.83 & 0.06 \\
\hline 10. I can notice an unpleasant body sensation without worrying about it. & 0.44 & 0.05 \\
\hline \multicolumn{3}{|l|}{ Attention Regulation } \\
\hline II. I can pay attention to my breath without being distracted by things happening around me. & 0.61 & 0.03 \\
\hline 12. I can maintain awareness of my inner bodily sensations even when there is a lot going on around me. & 0.72 & 0.03 \\
\hline 13. When I am in conversation with someone, I can pay attention to my posture. & 0.62 & 0.03 \\
\hline 14. I can return awareness to my body if I am distracted. & 0.78 & 0.02 \\
\hline 15. I can refocus my attention from thinking to sensing my body. & 0.79 & 0.02 \\
\hline 16. I can maintain awareness of my whole body even when a part of me is in pain or discomfort. & 0.71 & 0.03 \\
\hline 17. I am able to consciously focus on my body as a whole. & 0.80 & 0.02 \\
\hline \multicolumn{3}{|l|}{ Emotional Awareness } \\
\hline 18. I notice how my body changes when I am angry. & 0.63 & 0.03 \\
\hline 19. When something is wrong in my life, I can feel it in my body. & 0.66 & 0.03 \\
\hline 20. I notice that my body feels different after a peaceful experience. & 0.88 & 0.01 \\
\hline 2I. I notice that my breathing becomes free and easy when I feel comfortable. & 0.86 & 0.02 \\
\hline 22. I notice how my body changes when I feel happy/joyful. & 0.92 & 0.01 \\
\hline \multicolumn{3}{|l|}{ Self-Regulation } \\
\hline 23. When I feel overwhelmed I can find a calm place inside. & 0.74 & 0.02 \\
\hline 24. When I bring awareness to my body I feel a sense of calm. & 0.85 & 0.02 \\
\hline 25. I can use my breath to reduce tension. & 0.68 & 0.03 \\
\hline 26. When I am caught up in thoughts, I can calm my mind by focusing on my body/breathing. & 0.82 & 0.02 \\
\hline \multicolumn{3}{|l|}{ Body Listening } \\
\hline 27. I listen for information from my body about my emotional state. & 0.79 & 0.02 \\
\hline 28. When I am upset, I take time to explore how my body feels. & 0.82 & 0.02 \\
\hline 29. I listen to my body to inform me about what to do. & 0.75 & 0.02 \\
\hline \multicolumn{3}{|l|}{ Trusting } \\
\hline 30. I am at home in my body. & 0.64 & 0.04 \\
\hline 3I. I feel my body is a safe place. & 0.78 & 0.03 \\
\hline 32. I trust my body sensations. & 0.75 & 0.03 \\
\hline
\end{tabular}

Abbreviations: SE, standard error; CFA, Confirmatory factor analysis; MAIA, Multidimensional Assessment of Interoceptive Awareness.

scales, which, in part, could be attributed to the low reliability of these two scales. However, in assessing convergent validity, the MAIA scale Not Distracting was (negatively) well-converging with an ignoring coping style, and Not Worrying was (negatively) well-converging with catastrophizing, perceived stress, and depression. These correlations appear to be strongest in the current pain subsample (patients who considered themselves not fully recovered after 2 years and reported pain in the past week). Thus, despite lower internal consistency, these scales appear to have some construct validity, particularly in individuals with recurrent or chronic pain.

\section{Differences between known groups}

When comparing POP study primary care patients with our original validation sample of individuals who were experienced in mind-body therapies, mind-body trained individuals scored significantly higher on all eight scales, suggesting they may be more often aware of body sensations, tend to ignore or distract themselves less often from pain or discomfort, tend to worry less often with sensations of pain and discomfort, are more often able to sustain and control attention to body sensation, are more often aware of the connection between body sensations and emotional states, listen more often to the 


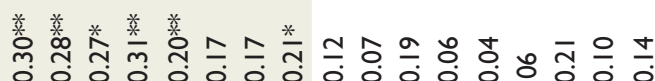

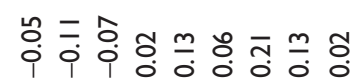

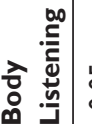

능 =

을

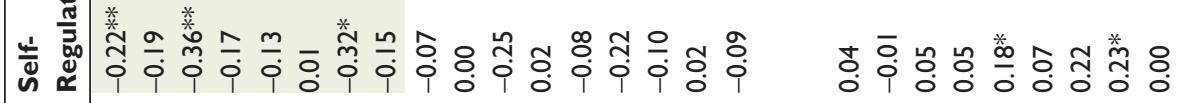

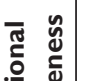

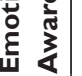

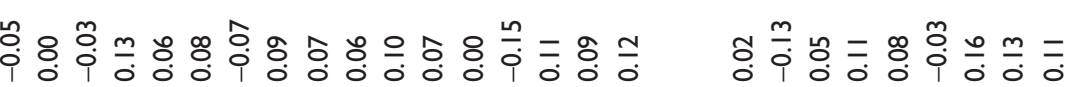

ᄃ

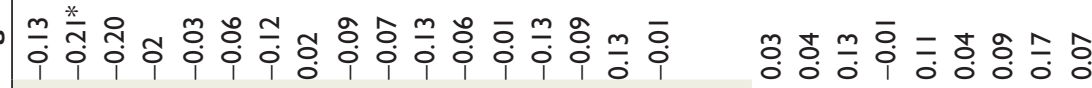

$\stackrel{\infty}{\Xi}$

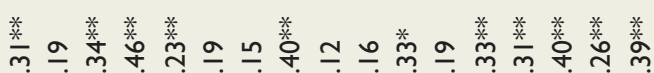

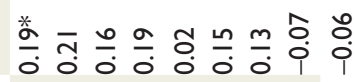

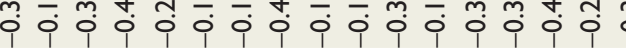

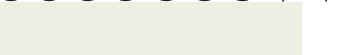

웅웅요

$\overline{0}$

î

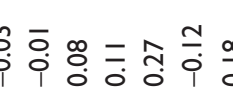

恙

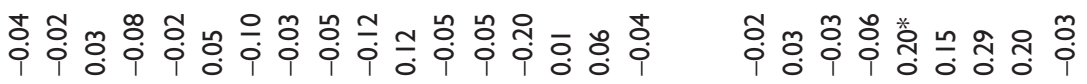

吾

旁

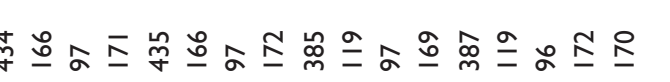

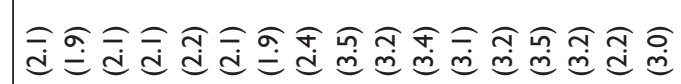

গิ

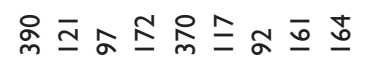

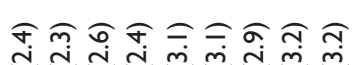

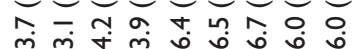

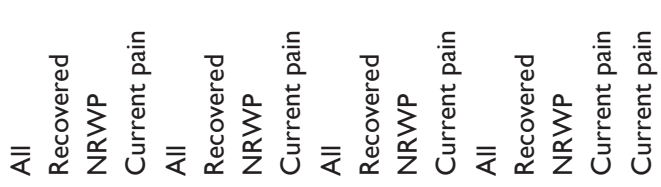

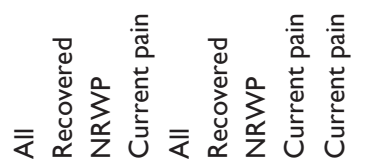

马

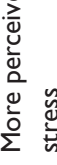

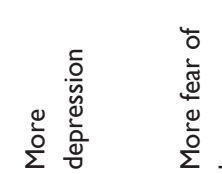

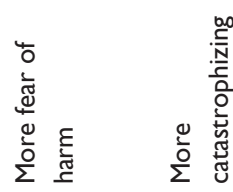

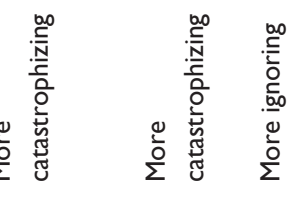

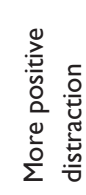

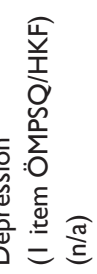

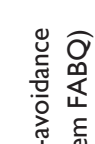
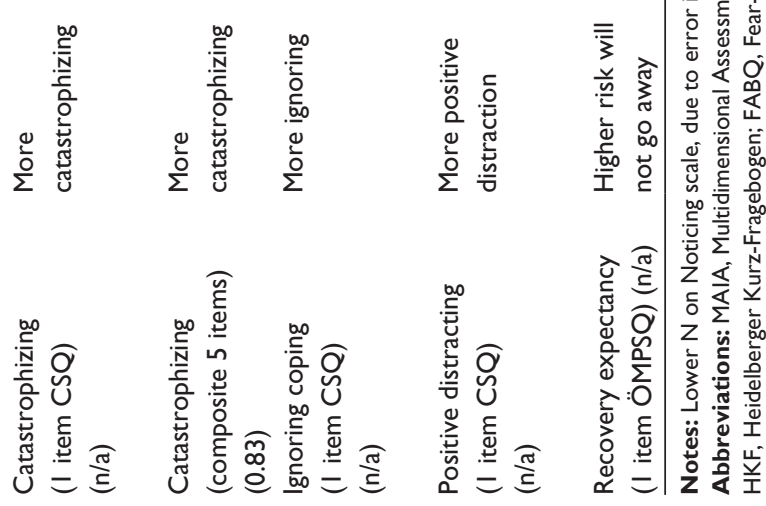
Table 7 Mean scores on MAIA scales of POP and mind-body samples

\begin{tabular}{|c|c|c|c|c|}
\hline MAIA scale & $\begin{array}{l}\text { POP total sample } \\
N=304-435^{a}\end{array}$ & $\begin{array}{l}\text { POP sample without practice } \\
N=253-364\end{array}$ & $\begin{array}{l}\text { POP sample with practice } \\
N=5|-7|\end{array}$ & $\begin{array}{l}\text { Mind-body sample } \\
\mathrm{N}=318-325\end{array}$ \\
\hline Noticing & $3.58(1.16)^{* *}$ & $3.49(1.21)^{* *}$ & $4.03(0.79)^{\mathrm{b}}$ & $3.94(0.59)$ \\
\hline Not Distracting & $1.91(1.00)^{* *}$ & $1.90(1.00)^{* *}$ & $1.96(1.72)^{* *}$ & $3.20(0.87)$ \\
\hline Not Worrying & $2.91(1.08)^{* *}$ & $2.90(1.08)^{* *}$ & $3.02(1.14)$ & $3.27(0.84)$ \\
\hline Attention Regulation & $3.04(1.05)^{* *}$ & $2.95(1.06)^{* *}$ & $3.37(0.93)^{*, b}$ & $3.79(0.64)$ \\
\hline Emotional Awareness & $3.42(1.20)^{* *}$ & $3.34(1.22)^{* *}$ & $3.90(0.98)^{b}$ & $4.16(0.64)$ \\
\hline Self-Regulation & $2.93(1.19)^{* *}$ & $2.80(1.18)^{* *}$ & $3.60(0.99)^{\mathrm{b}}$ & $3.86(0.74)$ \\
\hline Body Listening & $2.5 \mathrm{I}(\mathrm{I} .28)^{* *}$ & $2.38(1.28)^{* *}$ & $3.14(1.16)^{b}$ & $3.50(0.87)$ \\
\hline Trusting & $3.91(0.97)^{* *}$ & $3.84(0.98)^{* *}$ & $4.22(0.8 \mathrm{I})^{\mathrm{b}}$ & $4.13(0.74)$ \\
\hline
\end{tabular}

Notes: All scales are scored so that a higher score is more positive interoceptive awareness; possible range is from 0 to 5 . $* P<0.0$ I; $* * P<0.00$ I, for comparisons with mind-body sample by $t$ test for unadjusted means. (Adjustment for age, sex, ethnicity, and education left all $P<0.00 \mathrm{I}$, except Trusting, $P=0.003$.) ${ }^{\mathrm{a} D u e}$ to an administrative error, I 35 participants were not asked the four items of the Noticing scale, resulting in a lower $N$ for this scale. ${ }^{b} P<0.00$ I, for comparisons of the two POP subsamples with and without ongoing mind-body practice, by $t$ test for unadjusted means.

Abbreviations: MAIA, Multidimensional Assessment of Interoceptive Awareness; POP, Prognosis of Pain study.

body for insight, and experience their body more often as safe and trustworthy. The between-sample difference is particularly large on the Not Distracting scale. All primary care patients who had experienced pain, even those with an ongoing mindbody practice, appear to see more value in a distraction style of coping with pain and discomfort than mind-body therapytrained individuals. Thus, the MAIA showed good ability to discriminate between these two samples.

We noted differences in responses to questions related to coping with pain. Irrespective of mode of administration (phone versus Internet), for primary care participants, scores on the Not Distracting scale were clearly lower than in the original validation sample study of mind-body experienced participants, and the Not Distracting scale was independent of all other MAIA scales.

However, in the original validation sample study with mind-body experienced participants, Not Distracting was positively correlated with the other aspects of interoceptive awareness. ${ }^{22}$ These findings appear to be consistent with the above suggestion that, contrary to the original validation sample of mind-body therapy-trained respondents, participants with a past or current experience of pain may or may not use distraction, independent of other aspects of interoceptive awareness; but training in mind-body therapies appears to be associated with the tendency to less often distract oneself from sensations of pain or discomfort, which, in turn, is associated with increased scores for all other aspects of interoceptive awareness.

The difference between these two samples in regard to their view of distraction is reflected in different opinions in current psychological pain research. Attentional strategies of diversion, distraction, or experiential avoidance, although commonly used, ${ }^{45,46}$ have yielded contradictory results. ${ }^{15,20,47-50}$ As they are explored in more detail, particularly with chronic pain, it appears that distracting oneself may not always be helpful, although participants in our primary care POP study sample reportedly used it more often than the mind-body trained participants of our original validation sample. Neuroimaging studies have shown that mindfulness meditators may be able to downregulate painful stimuli by increased sensory processing of the pain sensation itself, rather than by distraction away from it, and by replacing attempts to exert more cognitive control over the pain with a distinct brain state of cognitive disengagement. ${ }^{19}$ This is consistent with the view presented above that "turning away" from pain can be a problematic coping style with chronic pain. ${ }^{21}$ It is hypothetically possible that with training in mind-body therapies, some of which encourage direct experience of pain rather than thinking about it or averting attention, primary care patients may find that using mindful interoceptive awareness can be an advantageous coping style for pain and discomfort. This suggestion is consistent with recent experimental research ${ }^{20}$ and needs longitudinal assessment in a clinical setting.

MAIA scales appear to differentiate (1) between mostly mind-body therapy-naïve primary care patients and mindbody therapy-experienced individuals and (2) between primary care patients with and without ongoing mind-body practice, rather than between subgroups of primary care patients in different states of recovery from pain. There was one intriguing exception: The group of patients who declared themselves as not recovered, despite reporting no pain and relatively low functional disability scores (Table 2), exhibited a significantly higher degree of worry compared to the group with recurrent or chronic pain. This could indicate that a relatively large group (22\%) of patients, having no pain and minimal disability after an episode of acute LBP, may fail to feel recovered because of worries about 
potential future pain. Only in this subgroup, Not Worrying was correlated with fear-avoidance; in addition, this subgroup showed the strongest correlation between Not Worrying and catastrophizing, which may distinguish this group from chronic pain patients. For example, in a study of chronic pain, it was found that worry was associated with an increased vigilance toward pain sensations rather than an increased disposition to general worry and anxiety. ${ }^{51}$ Our results suggest that in this subgroup, worry was not related to depression, and the severities of perceived stress and depression were more closely associated with deficits in emotion regulation. Furthermore, as we found only differences in scale scores between pain recovery-related subgroups for one of the eight MAIA dimensions, current pain status among previously diagnosed pain patients does not appear to have a major influence on self-reported levels of interoceptive awareness.

As it is long known in survey research, ${ }^{52}$ phone interviewing is biased toward social desirability ${ }^{53}$ and agreement response set, ${ }^{55}$ and, accordingly, our phone sample scored consistently higher than the Internet sample on the MAIA scales. Differences between subsamples were markedly smaller than the differences between the entire POP sample and the mind-body-trained sample. Removing the POP phone sample would have increased these differences for most scales and further strengthened our results.

\section{Challenge of assessing learning processes}

The problem in measuring concepts such as interoceptive awareness is that gaining such awareness involves a learning process in which people at baseline do not know and are not yet able to understand or articulate fully the skills they will acquire. Questions in self-report instruments that aim at measuring skills for which respondents have not yet developed appropriate concepts and language present the challenge that the concepts may be understood in different ways before experiencing a mind-body therapy compared to after. A good example of where this challenge was encountered and well described is the validation of the Five-Facets Mindfulness Questionnaire (FFMQ), in which the authors used a validation sample of mostly mindfulness-naïve students. ${ }^{55}$ They found that the items of one of the FFMQ's subscales, Observing, did not fit the CFA for the entire sample and that in nonmeditating individuals, relations between Observing and psychological adjustment were insignificant or in the opposite direction. The authors suggested that these items may not adequately capture the experience that is characteristic of mindfulness, or that this subscale is particularly sensitive to changes with meditation experience and represents a clear facet of mindfulness only as mindfulness skills further develop. Subsequent application in samples with meditation experience supported the validity of the Observe subscale for a population which had learned to meditate. ${ }^{56}$ In our study, it is thus possible that the aspect of Not Distracting oneself from the perception of pain or other sensations of discomfort may only become a dimension of interoceptive awareness when developed with a mind-body therapy..$^{19}$ Clearly, this problem of a change in the understanding of questionnaire items - from before to after an item-related learning process occurs - remains and may be but one example of a general limitation of self-report measures for these types of phenomena, a methodological problem for any self-report measure of a parameter that changes with learning and new experiences.

\section{Suggestions for further refinement}

Despite the difficulties the Not Distracting scale created for the CFA in the entire study sample, we would not suggest eliminating this scale from the multidimensional MAIA instrument. The striking difference between the body awareness-naïve primary care pain patient sample and the original mind-body validation sample in the understanding of the items for this dimension appears particularly interesting and warrants further scale refinement. Instead of its elimination, we suggest that Item 5 be rephrased ("I ignore" instead of "I do not notice"), and that a few positively worded items be added to the three-item scale to potentially improve its reliability. Second, we suggest that respondents be given the questionnaire in writing, with visual reference for the response options, rather than have items presented verbally without accompaniment. Assessing attentional strategies for their role in the complex management of pain is becoming a key element for pain research and will require refinement that goes well beyond the scope of this study.

With these suggestions for further refinement, we believe that the strong confirmation of six of the eight MAIA scales in this mind-body therapy-naïve sample of patients with past or current pain provides sufficient validity for the MAIA to suggest its application in longitudinal studies of mind-body therapies for pain patients.

\section{Limitations}

Several limitations need to be acknowledged: first, as already discussed, the inclusion of the MAIA scales into the 2-year follow-up survey of the POP cohort study was different from an earlier follow-up interview and, therefore, was somewhat unexpected for the participants. Second, the survey was conducted in two different modes of application, over the phone 
or online. As stated above, items presented over the phone did not have a visual reference and may have been more difficult to answer. Participants who did not fully understand a question would have to interrupt the flow of the survey to ask the interviewer for clarification, whereas participants reading a confusing question online could simply reread it. We had not anticipated that these survey styles could potentially lead to different levels of clarity in the item presentation. However, the observed differences provided important suggestions for future applications of the MAIA scales. Third, we are not able to compare the two groups on other psychological parameters to test whether differences in the MAIA scale scores are due to differences in other factors, such as catastrophizing, and whether the MAIA provides additional value above a measure of catastrophizing. Fourth, to make space for the MAIA, we reduced the number of psychological items we had used in this cohort in earlier surveys. Additional validity measures one would have chosen to assess the comparative and incremental validity of the scales (Pain Catastrophizing Scale; ${ }^{43}$ Pain Vigilance Awareness Questionnaire ${ }^{58}$ ) further could not be included in the ongoing cohort study, so we were limited in conducting additional, more detailed construct validity assessments for this population. Fifth, self-report of a construct that one may not be aware of is particularly sensitive to beliefs, social desirability, and bias and therefore will need to be validated against objective measures. Lastly, sensitivity to change of the MAIA scales, in particular with interventions claiming to enhance body awareness, needs to be assessed in longitudinal studies. These studies are currently under way.

\section{Conclusion}

The data presented in this cross-sectional study suggest a hypothesis for further research with pain patients, namely the notion that training in mind-body approaches may lead to a different coping style with pain, possibly based on a different style of interoceptive attention regulation. This notion is not new and has been suggested by research with experimental acute pain. ${ }^{20}$ Longitudinal studies in a clinical population are necessary to determine whether a less distracting and more mindful style of attention, as suggested in the mind-body therapy experiences sample, may be feasible and superior to the more commonly practiced distracting-attention style in the treatment and prevention of chronic pain. The MAIA may help in answering this important question and be a valid instrument for the quantitative assessment of some of the qualities and skills individuals may experientially learn when undergoing mindbody therapies. Due to the complexity of the construct and the inherent challenges in its assessment, we view the MAIA scales as a starting point for further refinement through additional research rather than as a finished product. This multifaceted instrument has the potential of serving an important function for psychosomatic research, when therapeutic interventions, eg, for the management of pain, directly aim at the interface of body and mind. Key applications for the MAIA scales would be in studies of nonpharmacological approaches for the treatment or prevention of chronic LBP to assess changes in interoceptive awareness as a potential mechanism of action.

\section{Disclosure}

The authors report no conflicts of interest in this work.

\section{References}

1. Craig AD. How do you feel? Interoception: the sense of the physiological condition of the body. Nat Rev Neurosci. 2002;3(8):655-666.

2. Jylhä M. What is self-rated health and why does it predict mortality? Towards a unified conceptual model. Soc Sci Med. 2009;69(3):307-316.

3. Cioffi D, Holloway J. Delayed costs of suppressed pain. J Pers Soc Psychol. 1993;64(2):274-282.

4. Zeidan F, Martucci KT, Kraft RA, Gordon NS, McHaffie JG, Coghill RC. Brain mechanisms supporting the modulation of pain by mindfulness meditation. J Neurosci. 2011;31(14):5540-5548.

5. Wade JB, Price DD, Hamer RM, Schwartz SM, Hart RP. An emotional component analysis of chronic pain. Pain. 1990;40(3):303-310.

6. Cauda F, Torta DM, Sacco K, et al. Shared "core" areas between the pain and other task-related networks. PLoS One. 2012;7(8):e41929.

7. Craig AD. Pain mechanisms: labeled lines versus convergence in central processing. Annu Rev Neurosci. 2003;26:1-30.

8. Craig AD. A new view of pain as a homeostatic emotion. Trends Neurosci. 2003;26(6):303-307.

9. Craig AD. How do you feel - now? The anterior insula and human awareness. Nat Rev Neurosci. 2009;10(1):59-70.

10. Damasio A. The Feeling of What Happens: Body and Emotion in the Making of Consciousness. San Diego: Harcourt; 1999.

11. Hasenbring MI, Verbunt JA. Fear-avoidance and endurance-related responses to pain: new models of behavior and their consequences for clinical practice. Clin J Pain. 2010;26(9):747-753.

12. Vlaeyen JW, Linton SJ. Fear-avoidance model of chronic musculoskeletal pain: 12 years on. Pain. 2012;153(6):1144-1147.

13. McCracken LM, Keogh E. Acceptance, mindfulness, and values-based action may counteract fear and avoidance of emotions in chronic pain: an analysis of anxiety sensitivity. J Pain. 2009;10(4):408-415.

14. Hasenbring MI, Hallner D, Rusu AC. Fear-avoidance- and endurance-related responses to pain: development and validation of the Avoidance-Endurance Questionnaire (AEQ). Eur J Pain. 2009;13(6): 620-628.

15. Flink IK, Nicholas MK, Boersma K, Linton SJ. Reducing the threat value of chronic pain: A preliminary replicated single-case study of interoceptive exposure versus distraction in six individuals with chronic back pain. Behav Res Ther. 2009;47(8):721-728.

16. Hasenbring M. Attentional control of pain and the process of chronification. Prog Brain Res. 2000;129:525-534.

17. Eccleston C, Crombez G, Aldrich S, Stannard C. Attention and somatic awareness in chronic pain. Pain. 1997;72(1-2):209-215.

18. Eccleston C, Crombez G. Attention and pain: merging behavioral and neuroscience investigations. Pain. 2005;113(1-2):7-8.

19. Gard T, Holzel BK, Sack AT, et al. Pain attenuation through mindfulness is associated with decreased cognitive control and increased sensory processing in the brain. Cereb Cortex. 2012;22(11):2692-2702. 
20. Johnston NE, Atlas LY, Wager TD. Opposing effects of expectancy and somatic focus on pain. PLoS One. 2012;7(6):e38854.

21. Williams JM. Mindfulness and psychological process. Emotion. 2010;10(1):1-7.

22. Mehling WE, Price C, Daubenmier JJ, Acree M, Bartmess E, Stewart A. The Multidimensional Assessment of Interoceptive Awareness (MAIA). PLoS One. 2012;7(11):e48230.

23. Craig AD. Interoception: the sense of the physiological condition of the body. Curr Opin Neurobiol. 2003;13(4):500-505.

24. Baas LS, Beery TA, Allen G, Wizer M, Wagoner LE. An exploratory study of body awareness in persons with heart failure treated medically or with transplantation. J Cardiovasc Nurs. 2004;19(1):32-40.

25. Cameron OG. Interoception: the inside story - a model for psychosomatic processes. Psychosom Med. 2001;63(5):697-710.

26. Verdejo-Garcia A, Clark L, Dunn BD. The role of interoception in addiction: a critical review. Neurosci Biobehav Rev. 2012;36(8): $1857-1869$.

27. Mehling WE, Gopisetty V, Daubenmier J, Price CJ, Hecht FM, Stewart A. Body awareness: construct and self-report measures. PLoS One. 2009;4(5):e5614.

28. Parkin L, Morgan R, Rosselli A, et al. Exploring the relationship between mindfulness and cardiac perception. Mindfulness. Epub 2013 Feb 5.

29. Khalsa SS, Rudrauf D, Damasio AR, Davidson RJ, Lutz A, Tranel D. Interoceptive awareness in experienced meditators. Psychophysiology. 2008;45(4):671-677.

30. Nielsen L, Kaszniak AW. Awareness of subtle emotional feelings: a comparison of long-term meditators and nonmeditators. Emotion. 2006;6(3):392-405.

31. Ceunen E, Van Diest I, Vlaeyen JW. Accuracy and awareness of perception: related, yet distinct (commentary on Herbert et al, 2012). Biol Psychol. 2013;92(2):426-427.

32. Mehling WE, Wrubel J, Daubenmier JJ, et al. Body awareness: a phenomenological inquiry into the common ground of mind-body therapies. Philos Ethics Humanit Med. 2011;6:6.

33. Flor H. New developments in the understanding and management of persistent pain. Curr Opin Psychiatry. 2012;25(2):109-113.

34. Holzel BK, Lazar SW, Gard T, Schuman-Olivier Z, Vago DR, Ott U. How does mindfulness meditation work? Proposing mechanisms of action from a conceptual and neural perspective. Perspect Psychol Sci. 2011;6(6):537-559.

35. Mehling WE, Gopisetty V, Bartmess E, et al. The prognosis of acute low back pain in primary care in the United States: a 2-year prospective cohort study. Spine (Phila Pa 1976). 2012;37(8):678-684.

36. surveygizmo.com [homepage on the Internet]. Widgix LLC, 4888 Pearl East Cir, Suite 399 W, Boulder, CO 80301, USA; 2010. Available from: http://www.surveygizmo.com. Accessed May 2010.

37. Beurskens AJ, de Vet HC, Köke AJ. Responsiveness of functional status in low back pain: a comparison of different instruments. Pain. 1996;65(1):71-76.

38. Cohen S. Perceived Stress Scale (PSS). http://www.psy.cmu. edu/ scohen/PSS.html. Accessed May 2010.

39. Linton SJ, Halldén K. Can we screen for problematic back pain? A screening questionnaire for predicting outcome in acute and subacute back pain. Clin J Pain. 1998;14(3):209-215.

40. Neubauer E, Junge A, Pirron P, Seemann H, Schiltenwolf M. HKF-R 10 - screening for predicting chronicity in acute low back pain (LBP): a prospective clinical trial. Eur J Pain. 2006;10(6):559-566.

41. Waddell G, Newton M, Henderson I, Somerville D, Main CJ. A FearAvoidance Beliefs Questionnaire (FABQ) and the role of fear-avoidance beliefs in chronic low back pain and disability. Pain. 1993;52(2): $157-168$.

42. Jensen MP, Keefe FJ, Lefebvre JC, Romano JM, Turner JA. One- and two-item measures of pain beliefs and coping strategies. Pain. 2003; 104(3):453-469.

43. Sullivan MJL, Bishop SR, Pivik J. The pain catastrophizing scale: Development and validation. Psychol Assess. 1995;7(4): $524-532$.
44. Muthén B, Muthén L. Mplus. http://www.statmodel.com. [webpage on the Internet]. Accessed February 2011.

45. Leventhal H. I know distraction works even though it doesn't! Health Psychol. 1992;11(4):208-209.

46. Eccleston C. Chronic pain and distraction: an experimental investigation into the role of sustained and shifting attention in the processing of chronic persistent pain. Behav Res Ther. 1995;33(4):391-405.

47. Van Damme S, Legrain V, Vogt J, Crombez G. Keeping pain in mind: a motivational account of attention to pain. Neurosci Biobehav Rev. 2010;34(2):204-213.

48. Jackson T, Yang Z, Li X, Chen H, Huang X, Meng J. Coping when pain is a potential threat: the efficacy of acceptance versus cognitive distraction. Eur J Pain. 2012;16(3):390-400.

49. Goubert L, Crombez G, Eccleston C, Devulder J. Distraction from chronic pain during a pain-inducing activity is associated with greater post-activity pain. Pain. 2004;110(1-2):220-227.

50. Snijders TJ, Ramsey NF, Koerselman F, van Gijn J. Attentional modulation fails to attenuate the subjective pain experience in chronic, unexplained pain. Eur J Pain. 2010;14(3):282. e1-e10.

51. Eccleston C, Crombez G, Aldrich S, Stannard C. Worry and chronic pain patients: a description and analysis of individual differences. Eur J Pain. 2001;5(3):309-318.

52. Couper MP. The future of modes of data collection. Public Opin $Q$. 2011;75(5):889-908.

53. Acree M, Ekstrand M, Coates TJ, Stall R. Mode effects in surveys of gay men: a within-individual comparison of responses by mail and by telephone. J Sex Res. 1999;36(1):67-75.

54. Jordan LA, Marcus AC, Reeder LG. Response styles in telephone and household interviewing: a field experiment. Public Opin Q. 1980;44(2): 210-222.

55. Baer RA, Smith GT, Hopkins J, Krietemeyer J, Toney L. Using selfreport assessment methods to explore facets of mindfulness. Assessment. 2006;13(1):27-45.

56. Baer RA, Smith GT, Lykins E, et al. Construct validity of the five facet mindfulness questionnaire in meditating and nonmeditating samples. Assessment. 2008;15(3):329-342.

57. Sherman KJ, Cherkin DC, Erro J, Miglioretti DL, Deyo RA. Comparing yoga, exercise, and a self-care book for chronic low back pain: a randomized, controlled trial. Ann Intern Med. 2005;143(12): 849-856.

58. McCracken LM. 'Attention' to pain in persons with chronic pain: a behavioral approach. Behav Ther. 1997;28:271-284.

59. Kabat-Zinn J, Lipworth L, Burney R. The clinical use of mindfulness meditation for the self-regulation of chronic pain. J Behav Med. 1985; 8(2):163-190.

60. Brown CA, Jones AK. Meditation experience predicts less negative appraisal of pain: electrophysiological evidence for the involvement of anticipatory neural responses. Pain. 2010;150(3):428-438.

61. Morone NE, Greco CM, Weiner DK. Mindfulness meditation for the treatment of chronic low back pain in older adults: a randomized controlled pilot study. Pain. 2008;134(3):310-319.

62. McCracken LM, Zhao-O'Brien J. General psychological acceptance and chronic pain: there is more to accept than the pain itself. Eur J Pain. 2010;14(2):170-175.

63. Steen E, Haugli L. From pain to self-awareness - a qualitative analysis of the significance of group participation for persons with chronic musculoskeletal pain. Patient Educ Couns. 2001;42(1):35-46.

64. Haugstad GK, Haugstad TS, Kirste UM, et al. Posture, movement patterns, and body awareness in women with chronic pelvic pain. J Psychosom Res. 2006;61(5):637-644.

65. Haugstad GK, Haugstad TS, Kirste UM, et al. Continuing improvement of chronic pelvic pain in women after short-term Mensendieck somatocognitive therapy: results of a 1-year follow-up study. Am J Obstet Gynecol. 2008;199(6):615. e1-e8.

66. Gard G. Body awareness therapy for patients with fibromyalgia and chronic pain. Disabil Rehabil. 2005;27(12):725-728. 
67. Gustafsson M, Ekholm J, Ohman A. From shame to respect: musculoskeletal pain patients' experience of a rehabilitation program, a qualitative study. Journal of Rehabil Med. 2004;36(3):97-103.

68. Price CJ, McBride B, Hyerle L, Kivlahan DR. Mindful awareness in body-oriented therapy for female veterans with post-traumatic stress disorder taking prescription analgesics for chronic pain: a feasibility study. Altern Ther Health Med. 2007;13(6):32-40.

69. Ernst E, Canter PH. The Alexander technique: a systematic review of controlled clinical trials. Forsch Komplementarmed Klass Naturheilkd. 2003;10(6):325-329.
70. Little P, Lewith G, Webley F, et al. Randomized controlled trial of Alexander technique lessons, exercise, and massage (ATEAM) for chronic and recurrent back pain. BMJ. 2008;337:a884.

71. Mehling WE, Hamel KA, Acree M, Byl N, Hecht FM. Randomized, controlled trial of breath therapy for patients with chronic low-back pain. Altern Ther Health Med. 2005;11(4):44-52. 


\section{Supplementary material}

Table SI Psychological measures (All scales, 0-10)

\begin{tabular}{|c|c|c|}
\hline Parameter & $\operatorname{Item}(\mathbf{s})$ & Source \\
\hline Perceived stress & $\begin{array}{l}\text { - In the last month, how often have you felt that you were unable to control the } \\
\text { important things in your life? } \\
\text { - In the last month, how often have you felt that things were going your way? } \\
\text { - In the last month, how often have you felt difficulties were piling up so high } \\
\text { that you could not overcome them? } \\
\text { - In the last month, how often have you felt confident about your ability to handle } \\
\text { your personal problems? }\end{array}$ & $\mathrm{PSS}^{\prime}$ \\
\hline Depression & How much have you been bothered by feeling down or depressed in the past week? & ÖMPSQ, ${ }^{2} \mathrm{HKF}^{3}$ \\
\hline Fear-avoidance beliefs & Do you feel bending, lifting, walking, or driving might harm your back? & $\mathrm{FABQ}^{4}$ \\
\hline \multirow[t]{6}{*}{ Catastrophizing } & A. - You think it is terrible and you feel it is never going to get any better. & $\mathrm{CSQ}^{5}$ \\
\hline & B. - You think it is terrible, and you feel it is never going to get any better. & $\mathrm{CSQ}^{5}$ \\
\hline & - You wondered whether something serious may happen. & $\mathrm{PCS}^{6}$ \\
\hline & - You feel you can't go on. & $\mathrm{PCS}^{6}$ \\
\hline & - You wondered whether you have the same bad disease as somebody you know. & $\mathrm{HKF}^{3}$ \\
\hline & - You wondered whether there is a bad disease behind all this pain. & $\mathrm{HKF}^{3}$ \\
\hline Recovery expectancy & In your view, how large is the risk that your current pain may not go away? & ÖMPSQ ${ }^{2}$ \\
\hline \multirow[t]{2}{*}{ Ignoring coping style } & When you feel back pain, on a scale of 0 to 10 , how much do you do the following: & $\mathrm{CSQ}^{5}$ \\
\hline & When you feel pain you ignore it? & \\
\hline Positive distraction & You do something you enjoy, such as watching TV or listening to music. & $\mathrm{CSQ}^{5}$ \\
\hline
\end{tabular}

Abbreviations: PSS, Perceived Stress Scale; ÖMPSQ, Örebro Musculoskeletal Pain Screening Questionnaire; HKF, Heidelberger Kurz-Fragebogen; FABQ, Fear-Avoidance Beliefs Questionnaire; CSQ, Coping Strategies Questionnaire; PCS, Pain Catastrophizing Scale.

\section{References}

1. Cohen S. Perceived Stress Scale (PSS). http://www.psy.cmu.edu/ scohen/ PSS.html. Accessed May, 2010.

2. Linton SJ, Halldén K. Can we screen for problematic back pain? A screening questionnaire for predicting outcome in acute and subacute back pain. Clin J Pain. 1998;14(3):209-215.

3. Neubauer E, Junge A, Pirron P, Seemann H, Schiltenwolf M. HKF-R 10 - screening for predicting chronicity in acute low back pain (LBP): a prospective clinical trial. Eur J Pain. 2006;10(6):559-566.
4. Waddell G, Newton M, Henderson I, Somerville D, Main CJ. A FearAvoidance Beliefs Questionnaire (FABQ) and the role of fear-avoidance beliefs in chronic low back pain and disability. Pain. 1993;52(2): $157-168$

5. Jensen MP, Keefe FJ, Lefebvre JC, Romano JM, Turner JA. One- and two-item measures of pain beliefs and coping strategies. Pain. 2003; 104(3):453-469.

6. Sullivan MJL, Bishop SR, Pivik J. The Pain Catastrophizing Scale: Development and validation. Psychol Assess. 1995;7(4):524-532.
Journal of Pain Research

\section{Publish your work in this journal}

The Journal of Pain Research is an international, peer-reviewed, open access, online journal that welcomes laboratory and clinical findings in the fields of pain research and the prevention and management of pain. Original research, reviews, symposium reports, hypothesis formation and commentaries are all considered for publication.

\section{Dovepress}

The manuscript management system is completely online and includes a very quick and fair peer-review system, which is all easy to use. Visit http://www.dovepress.com/testimonials.php to read real quotes from published authors. 